\title{
Aproximación al origen y desarrollo del periodismo de investigación en Andalucía
}

\author{
Dr. Ramón Reig \\ Profesor Titular de Estructura de la Información Periodística \\ Universidad de Sevilla
}

Se trata del primer acercamiento al tema desde la óptica de relacionar el contexto histórico con el quehacer periodístico y literario. El artículo nos va a mostrar como existía una relación evidente entre escritores y periodismo indagador en lo que el autor considera los inicios en Andalucía del citado tipo de periodismo. Se ofrecen además casos actuales y testimonios en los que los periodistas andaluces de nuestros días dan a conocer sus opiniones, estrategias y técnicas de trabajo.

\section{1.- Introducción}

To tengo conocimiento de ninguna publicación que trate monográficamente acerca de los orígenes y desarrollo del periodismo de investigación en Andalucía y menos de que en esa hipotética publicación se hayan recogido testimonios de periodistas que hayan llevado a cabo alguna tarea concreta de indagación periodística desde Andalucía. El presente texto pretende aportar unos mínimos apuntes al respecto.

Es evidente que el tema puede abrir una línea de investigación interesante, una línea que, como tantas otras en lo que se refiere a la comunicación y el periodismo en Andalucía, espera a que sea desarrollada y consolidada. De otro lado, asumo desde este momento las carencias que, con toda seguridad, se van a observar en este artículo. Me refiero a que soy consciente de trabajos periodísticos indagatorios que se han publicado en Andalucía en los momentos actuales pero que no van a ser abordados aquí. Es el reto que dejo para otros trabajos y con el que desafío a otros investigadores.

Se trata pues de colocar unas mínimas bases de trabajo. Pretendo ceñirme, casi en exclusiva, al quehacer periodístico de investigación en prensa, es decir, sobre papel. Queda terreno, mucho terreno, no sólo en la propia prensa andaluza sino en el sector audiovisual andaluz, para seguir trabajando.

Me dispongo a trazar unos orígenes del periodismo de investigación que ha tenido a Andalucía como escenario, a pesar de que algunos de los protagonistas que se van a mencionar no sean andaluces. Es lo de menos. Lo que importa es que fue Andalucía el objetivo y el objeto de sus escritos. En un rápido repaso, llegaré 
a la actualidad. Para ello, dividiré la actividad periodística en bloques cronológicos que nos servirán de soporte contextual. A su vez, subdividiré el segundo de los bloques por temáticas concretas que hayan sido objeto de tratamiento periodístico.

Algunos de los protagonistas que descubrimos dentro de los bloques cronológicos son más conocidos como escritores que como periodistas. Sin embargo, su labor estuvo estrechamente relacionada con el periodismo y, más en concreto, con el periodismo de investigación. Nada extraño para quien ha profundizado mínimamente en la historia del periodismo ${ }^{1}$.

Pero este método de trabajo hay que completarlo y eso significa que lo primero que hay que dejar claro es qué entiendo por periodismo de investigación. Digámoslo con brevedad y la mayor claridad posible.

\section{Qué entendemos por periodismo de investigación}

Periodismo de investigación es una expresión que encierra, desde mi punto de vista, los siguientes elementos esenciales:

a) Observación y capacidad crítica del periodista (lo cual suele ir acompañado por la experiencia en la profesión-oficio).

b) Proceso de trabajo prolongado y especialmente profundo y complejo dadas las fuentes de información variadas que hay que utilizar y el contraste obligado de los datos.

c) Novedad en el tema o, al menos, una gran dosis de novedad u originalidad en su tratamiento.

d) Apoyo del medio de comunicación en el que el profesional trabaje ya que, como indican Merrill y otros ${ }^{2}$, este tipo de periodismo se adentra en facetas especiales y requiere de la paciencia tanto del periodista como del medio de comunicación en el que trabaje.

Los elementos anteriores son a la vez características que definen al periodismo de investigación, dejando por sentado que, como ya han indicado numerosos especialistas (Martínez Albertos, Montserrat Quesada, J.M. de Pablos, Pepe Rodríguez... $)^{3}$, en toda actividad periodística debe existir alguna dosis indagadora.

1 Siempre me ha parecido curiosa, aunque nada sorprendente conociendo algo la idiosincrasia estadounidense, ese supuesto invento, esa supuesta originalidad made in USA llamada Nuevo Periodismo de los años sesenta, en el que periodismo y literatura van de la mano. Si ceñimos el tema a tierras estadounidenses podría aceptarse pero es que da la impresión de que el fenómeno se ha tratado de exportar. Me pregunto entonces qué estab haciendo, por no citar a Larra, Gustavo Adolfo Bécquer cuando enviaba sus «crónicas» desde Veruela a $E l$ Contemporáneo, de Madrid.

2 MERRILL, LEE, FRIEDLANDER: Medios de comunicación social. Teoría y práctica en Estados Unidos y en el mundo, Fundación Germán Sánchez Ruipérez, Madrid, 1992.

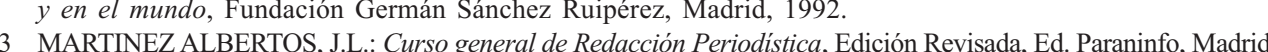
1992: QUESADA, Monserrat: Periodismo de investigación o el derecho a denunciar, Ed. Cims Barcelona, 1997; 1992; QUESADA, Monserrat. Periodismo de investigación o el derecho a denunciar, Ed. Cims, Barcelona, 1997; DE PABLOS, Jose Mand. : Periodismo de in in tica K. Periodismo de Investigacion, SEP-Facultad de Ciencias Sociales, Universidad de Vigo, 1998; RODRIGUEZ,
Pepe: Periodismo de investigación. Técnicas y estrategias, Ed. Paidós, Barcelona, 1994. 
De lo contrario, la información no la hace el periodista sino que se la hacen «otros» y desde ese mismo momento debo afirmar que el periodista deja de tener tal condición para convertirse en un copista, en un mensajero, sin más.

Creo que en la actualidad se hace poco periodismo de investigación a pesar de que algunos medios nos hablen de él para otorgarse prestigio. En el fondo, el periodismo de investigación no es rentable; el periodismo actual no observa, no estudia con detenimiento e intensidad las irregularidades y abusos que en algún lugar se estén cometiendo.

El periodismo se ha vuelto demasiado cómodo, centra sus denuncias sobre todo en los poderes públicos ignorando los poderes privados, salvo que se lleven a cabo operaciones de filtración interesada de datos de unos grupos contra otros. Entonces el periodismo entra más en la esfera de los intereses políticos reduccionistas $^{4}$ que en asuntos que realmente afecten a la sociedad.

El periodismo no suele anticiparse y denunciar continuamente asuntos y actuaciones «turbias» ligadas a concretos segmentos de poder o derivadas de determinadas estructuras. Pero estos son ya otros temas que nos desviarían del objeto del presente trabajo y que abordamos en un libro cuya salida está prevista para la primavera del año 2000.

Otra cuestión que hay que dejar clara es que no podemos comparar la labor de los que vamos a señalar como primeros investigadores periodísticos que trabajan sobre temas andaluces con la que se realiza en nuestros días, cuando se realiza. Ahora las estrategias son más sofisticadas, más abundantes. Si el periodista actual lo desea y su empresa lo apoya, puede desarrollar una investigación más profesional que la de finales del siglo XIX o primeras décadas del XX.

En definitiva, lo que se va a valorar aquí es la novedad del tema y la concentración y dedicación que le exige al periodista y/o escritor. Este aspecto es común tanto para el siglo XIX como para épocas posteriores hasta llegar a la actualidad.

4 En octubre y noviembre de 1999 el diario El Mundo «destapa» los detalles del «escándalo» Jesús Gil pero, en el fondo, y de paso, le hace el favor al Partido Popular de quitarle la competencia electoral del seño Gil ya que logra que éste renuncie a su pretensión de presentarse a las elecciones generales. La figura de Mario Conde tiene un éste renuncie a su pretensión de presentarse a las elecciones generales. La figura de Mario Conde tiene un tratamiento similar desde hace años pero esta vez por parte del diario El Pais. Uno y otro medio se suelen dedicar a publicar «casos de corrupción» que presentan como de interés público pero que casi siempre tienen un fondo común: hacer política pro PP y anti PSOE, o viceversa, antes que periodismo. El dia 9 de noviembre de 1999 El Mundo publicó que altos cargos del Ministerio de Fomento (en manos del PP) habían favorecido a familiares y conocidos en la adjudicación de ciertas obras. Esos alto cargos dimitieron. ¿Por qué «atacaba» El Mundo al PP? Porque de vez en cuando hay que dar sensación de independencia haciendo rodar cabezas de turco para incluso reforzar al propio PP. Lo «sorprendente» es que los medios del Grupo Prisa (la Cadena SER en este caso), que suelen ignorar a El Mundo negándole credibilidad, en esta ocasión se hicieron eco positivo de la noticia. Evidentemente, les era útil para,
de nuevo, hacer politica, contra el PP. Ahora resultaba que El Mundo sí era un medio creíble. 
3. Periodos históricos y periodismo de investigación en Andalucía

Cuando me he centrado en observar la actividad periodística de indagación en Andalucía a través de su historia más próxima, he llegado a la conclusión de que, para su estudio, podemos, grosso modo, dividirla en dos grandes periodos: el que va desde las postrimerías del siglo XIX hasta el final de la Guerra Civil española (1936-1939), y el que se prolonga desde los años cuarenta hasta la actualidad (años noventa). Como puede observarse, una división muy simplificada propia de una aproximación general al tema.

3.1. De las postrimerías del siglo XIX hasta el final de la Guerra Civil: el problema de la tierra

Un factor va a estar íntimamente unido a la actividad literaria y periodística de todo este tiempo: el problema de la tierra. A finales del siglo XIX y hasta la conclusión de la Guerra Civil, Andalucía es una zona geográfica donde el sector primario de la producción (o de la no producción y las desigualdades, he ahí el núcelo del problema de la tierra), va a tener un significado crucial.

La cuestión de la tierra se va a prolongar bastante más en el tiempo hasta llegar a nuestros días. En los años setenta las huelgas del verdeo, por ejemplo, aún eran noticia destacada en las páginas de los medios de comunicación de toda España. Las malas condiciones de los jornaleros eran denunciadas con relativa frecuencia y aún en la década de los noventa se han dado casos aislados en la provincia de Jaén. La primera legislatura del Parlamento de Andalucía (19821986) aprobará una Ley de Reforma Agraria que ya la Segunda República pretendía acometer pero que la Guerra Civil dejó en suspenso y así continuó hasta que comenzó de nuevo el debate tras la muerte de Franco y el inicio de la Transición (a partir de 1975).

También en los años setenta y ochenta la actividad sobre todo del Sindicato de Obreros del Campo (SOC), a través de la «toma» simbólica de fincas, cortes de carreteras, etc., fue recogida profusamente por los medios informativos. Sin embargo, a finales de los ochenta y hasta nuestros días, el problema jornalero va a ir remitiendo. Andalucía es ya una región donde el sector terciario o de servicios es esencial, como en cualquier sociedad moderna, y donde el sector «cuaternario» o de nuevas tecnologías de la comunicación, se desarrolla con relativa lentitud pero sobriamente a través del Parque Tecnológico de Andalucía, situado en Málaga, y del centro Cartuja 93, ubicado en Sevilla, en los mismos terrenos en los que tuvo lugar la celebración de la Exposición Universal de 1992.

Además, las exigencias de la Política Agraria Común (PAC), de la Unión Europea, y aspectos también negativos para el agro andaluz como los subsidios estatales y las irregularidades que llevan consigo, han influido decisivamente para que el problema del campo quede en suspenso.

Andalucía ya no es una tierra de jornaleros, como tópicamente la siguen considerando algunos, sino que de su población mayor de 16 años (unos 5,5 
millones de personas) tan sólo unas 250.000 personas se puede decir que tienen esta condición, puesto que el número de personas dedicadas a la agricultura es de aproximadamente 370.000 , si bien aquí hay que incluir a los propietarios de tierras. La población jornalera se concentra en determinadas áreas geográficas que, como se ha dicho, están subsidiadas por fondos estatales, lo que quiere decir que la mayoría de esta población forma parte de los aproximadamente 900.000 parados que, oficialmente, hay en Andalucía ${ }^{5}$.

Lo que se quiere decir con los datos anteriores es evidente: si el problema de la tierra llega hasta nuestros días (aunque la Reforma Agraria que se aprueba en la primera legislatura andaluza poco o nada tenga que ver con aquel proyecto sumamente intervencionista de la Segunda República), es fácil deducir que a finales del siglo XIX y hasta el término de la Guerra Civil dicho problema se convierte en un contexto crucial en el que van a desenvolverse determinados escritores y periodistas. El problema de la tierra está inevitablemente unido a la conflictividad social que, en no pocas ocasiones, toma aspectos de especial violencia y crueldad. Este entorno va a significar un punto de atracción lógico para el periodismo y para la literatura. Veamos algunos casos.

A finales del siglo XIX y principios del XX, escritores de renombre van a acudir a Andalucía para realizar tareas periodísticas. Leopoldo Alas «Clarín», asiste a procesos judiciales contra activistas del movimiento anarquista «La Mano Negra ${ }^{6}$ como enviado especial del diario madrileño El Día, que le encarga trabajos de indagación sobre el tema.

El escritor no se va a limitar a describir los hechos como asuntos de actualidad sino que, además, y como es lógico, se va a interesar por el contexto que los origina: la situación en el campo andaluz. Publicará sus conclusiones de forma anónima a lo largo de 1883 en El Día a través de una serie de artículos bajo títulos genéricos como «El hambre en Andalucía» o «La crisis de Andalucía», textos «con un marcado aire de modernidad» ${ }^{7}$.

El mismo tema -el problema de la tierra y sus consecuencias- es la causa de que José Martínez Ruiz «Azorín», publique artículos en El Imparcial (cinco entre

5 Véase Anuario Estadístico de Andalucía 1997, Consejería de Economía y Hacienda-Instituto de Estadística de Andalucía, Junta de Andalucía, Sevilla, 1997, p. 159 y ss.

6 Se suele atribuir a la actividad anarquista o, mejor dicho a ciertas corrientes de este movimiento, la creación de una organización secreta llamada «La Mano Negra» que fue desarticulada en Andalucía en 1883. Sus de una organización secreta llamada miembros actuaban contra los terratenientes de zonas como el marco de Jerez. El asunto aún permanece rodeado de cierto misterio pero de lo que no cabe duda es de que el gobierno de Sagasta aprovechó la ocasión para desarticular buena parte del movimiento obrero-campesino de Cadiz, Cordoba y Sevilla, muy influido entonces por el anarcocolectivismo y el anarcocomunismo. Un proceso llevado a cabo en Jerez contra «La Mano Negra», que toma su nombre de unos documentos hallados por la Guardia Civil en la propia Jerez con una mano negra pintada, terminó con varios ajusticiamientos y destierros.

BERNAL RODRIGUEZ, Manuel: «La Andalucía conocida por los españoles», en VV.AA.: Historia de Andalucía, Volumen VII, La Andalucía Contemporánea (1868-1983), Cupsa Editorial/Editorial Planeta, Barcelona, 1983, p. 307. 
el 3 y el 24 de abril de 1905) bajo el título «La Andalucía trágica». Azorín observa in situ el estado en que subsiste el campesinado andaluz, en plena efervescencia del movimiento anarquista, y denuncia incluso la ineficacia del recién creado Instituto de Reformas Sociales ${ }^{8}$.

También en 1905 la situación del campo andaluz (Jerez de la Frontera) aparece de manera realista y cruda esta vez en la novela de Vicente Blasco Ibáñez La bodega. Por cierto, en esta misma época -principios del siglo XX- un prolífico novelista andaluz, José Mas, desconocido para el llamado gran público, publicó varias novelas inspiradas en el medio rural andaluz ${ }^{9}$.

En 1933 se producen los sucesos de Casas Viejas (Cádiz) a los que Ramón J. Sender aplicó su visión literaria y romántica. Lo significativo para un estudioso de la comunicación y el periodismo es el título de su novela, Viaje a la aldea del crimen (documetal de Casas Viejas), publicada en Madrid en 1934, ya que, como se acaba de comprobar, se emplea el concepto «documental», que en la actualidad unimos sin vacilar al reporterismo, al periodismo de investigación o a trabajos audiovisuales divulgativos.

Sender narra los hechos sucedidos en Casas Viejas, una aldea del municipio de Medina Sidonia (Cádiz), cuando los jornaleros declararon una situación de comunismo libertario, tomaron el cuartel de la Guardia Civil, se hicieron con armamento y asesinaron a varios agentes. La posterior represión por parte de la propia Guardia Civil y las Fuerzas de Asalto del gobierno republicano ocasionó la muerte de tres agentes más al asaltar la casa donde Curro Cruz «Seisdedos», el líder de los sublevados, se había refugiado con su familia.

La quema y asalto de la casa dejó paso a una represión en la que murieron veintiún campesinos, doce de ellos fusilados sumarialmente. Historiadores como los franceses G. Brey y J. Maurice han investigado esta tragedia que llevó consigo la dimisión de Manuel Azaña como presidente de la Segunda República ${ }^{10}$. Igualmente, el periodista Antonio Ramos Espejo, al que nos referiremos más adelante, publicó en 1984 un libro de investigación: Después de Casas Viejas ${ }^{11}$, en el que

8 BERNAL, op. cit. p. 307-308.

José Mas era hijo del poeta Benito Mas y Prat, que nació en Ecija (Sevilla) en 1846 y murió en Sevilla en 1892, cuya obra, como la de tantos otros, se vio eclipsada por el resplandor que emitía la de Gustavo Adolfo Bécquer. Mas y Prat también es un completo desconocido. A lo sumo, el sevillano «medio» dirá que «le suena» porque hay una calle con su nombre junto a unos famosísimos, en todo el mundo, grandes almacenes. Algo es algo. Para esa pléyade de poetas afectados por la figura de Bécquer véase RODRIGUEZ BALTANAS, Enrique J.: Gavilla de poetas sevillanos, líricos, satíricos, clásicos y costumbristas del siglo XIX, Ed. Guadalmena, Sevilla, 1988.

10 Bernal, op. cit., pp. 309-310.

11 RAMOS ESPEJO, Antonio: Después de Casas Viejas, Ed. Argos Vergara, Barcelona, 1984. Recientemente, el nombre de Casas Viejas, que hab́ sido borado del mapa, ha vuelto a Medina Sidonia por petición el nom decinos y concesión de la Junta de An bón. Cas Viejas se ha llam los vecinos y cosion de la Junta de An cácad de los ragedias del primer tercio del siglo XX en España. 
pone de manifiesto el papel represivo del capitán Rojas, a quien años después vamos a encontrar en Granada al frente de la represión en cuyo contexto fue fusilado Federico García Lorca.

Poco después de Casas Viejas estallaría la Guerra Civil. Cuando en 1939 terminó con la victoria del general Franco se inició el largo paréntesis de cuarenta años en el que la actividad periodística estaría estrechamente vigilada por el nuevo régimen y la información era monopolio del Estado. Sin embargo, ahora podemos saber cómo, a pesar de todo, hubo algún caso aisladísimo en el que alguien, en Andalucía y bajo el pleno dominio franquista, llevó a cabo una actividad investigadora con métodos periodísticos.

\subsection{Desde el final de la Guerra Civil hasta nuestros días}

3.2.1. Brenan y la muerte de Lorca

El caso tal vez más significativo lo sabemos gracias a las investigaciones académicas del antes mencionado periodista y profesor Antonio Ramos Espejo. En su tesina y en su tesis doctoral ${ }^{12}$, ambas elaboradas bajo la dirección del Dr. José Manuel Gómez y Méndez, del Departamento de Periodismo de la Universidad de Sevilla, en el que actualmente es profesor el propio Ramos Espejo, nos expone la actividad que en 1949 desplegó el hispanista Gerald Brenan, quien decide en aquella oscura época, poco después de la victoria franquista, regresar a España desde Inglaterra, adonde se había marchado en plena Guerra Civil tras haber ejercido diversas tareas periodísticas para medios de comunicación fundamentalmente ingleses.

Brenan había conocido a Lorca y hasta su domicilio en tierras inglesas le llega la noticia de que su amigo había muerto en Granada durante la contienda española, sin ningún dato más concreto. La muerte de Lorca era entonces un asunto envuelto en el más absoluto silencio. Decide entonces regresar a España y lo primero que hace es tratar de saber lo que le ha ocurrido al poeta. Sus averiguaciones podemos conocerlas gracias al trabajo exhaustivo de Ramos Espejo quien indica:

«En un ambiente hostil, como es la España de la postguerra, un autor, cuya obra fundamental, El laberinto español, está prohibida en España y que además se había inclinado por el bando republicano y por lo tanto en contra del régimen de Franco, se expone a recorrer escenarios estrechamente vigilados, a hacer preguntas atrevidas, a entrevistar a gente que le pueda dar pistas sobre la tumba de Federico García Lorca. Realiza un trabajo de documentación y de campo, propio de un

12 RAMOS ESPEJO, Antonio: Gerald Brenan: primer investigador periodístico de la muerte de García Lorca tesina o trabajo de investigación dirigido por el Dr. José Manuel Gómez y Méndez, Departamento de Periodismo, Universidad de Sevilla, 1996. Inédita; RAMOS ESPEJO, Antonio: El periodismo en Gerald Brenan 1998. Inédita aú 1998. Inédita aún cuando doy el último repaso a este artículo en marzo de 2000. 
reportero de investigación. Son cuatro días de búsqueda y anotaciones en su cuaderno, de trabajar con sigilo; y una vez conseguidos los datos necesarios, marcharse del lugar para no hacer peligrar su situación personal ni el resultado de su investigación» ${ }^{13}$.

Alguien podría objetar que cuatro días son pocos para un trabajo de investigación periodístico. Pero hay que tener en cuenta las condiciones en que trabajaba Brenan quien, por otra parte, no perdió el tiempo desviándose del asunto que le ocupaba.

En la conclusión octava de su tesis doctoral, Ramos Espejo vuelve a describir el trabajo de Brenan en relación con la muerte de Lorca:

«Consideración aparte merece, en esta modalidad periodística de investigación de actualidad, su aportación, en 'La faz de España', al descubrimiento de la verdad sobre la muerte de García Lorca, que el franquismo mantenía secreta como una cuestión de Estado. En el capítulo sexto de esta obra, Brenan escribe su arriesgada investigación, llevada a cabo siguiendo todos los requisitos que hoy nos dicen los expertos que han de darse para adquirir la dimensión de esta modalidad periodística:

a) Documentación previa del tema objeto de investigación. Brenan conoce la sociedad granadina en la que ha de desenvolverse y el ambiente socio-político que rodea la muerte del poeta que él había conocido en los años veinte.

b) Lleva a cabo su investigación en cuatro días, en un ambiente hostil. El es un autor prohibido en España, que se mueve clandestinamente. Realiza un trabajo de campo, propio de un reportero de investigación. Son cuatro días de búsqueda y anotaciones en su cuaderno, de trabajar con sigilo y, una vez conseguidos los datos necesarios, marcharse del lugar para no hacer peligrar su situación personal ni el resultado de sus pesquisas.

c) Descubre fundamentalmente los primeros datos reveladores para su trabajo: que la tumba de García Lorca no está en el cementerio de Granada y que el poeta no había sido fusilado en las tapias de este lugar, como errónea o intencionadamente se había publicado; sino en un punto cercano a la fuente de Ainadamar, en un barranco limítrofe entre los dos pueblos de Viznar y Alfacar. Allí fue fusilado y enterrado.

d) El investigador aporta también dos nombres, que son la clave para entender el cúmulo de circunstancias adversas y la polémica que se origina entre falangistas y cedistas, no ya sólo de Granada, sino de todo el país: la familia de Luis Rosales, en cuyo domicilio se esconde el poeta y donde creía estar más seguro por la importante vinculación de algunos de sus miembros a la Falange; y,

13 RAMOS ESPEJO, Antonio: Gerald Brenan: primer investigador periodistico de la muerte de García Lorca, trabajo de investigación inédito, Departamento de Periodismo, Universidad de Sevilla, pp. 232-233. 
por otra parte, el nombre de Ramón Ruiz Alonso, ex linotipista del periódico local, Ideal, y ex diputado de la CEDA.

e) Brenan es el primero en publicar el resultado de sus investigaciones en este capítulo de "The Face of Spain», en 1950, y en la Prensa. Con sus publicaciones, desmonta la versión oficial del régimen de Franco, difundida, entre otros, por José María Pemán, que responsabilizaba de los hechos a unos desconocidos Lorca, como deja bien claro el investigador, estaba vinculado a la izquierda: su cuñado, Fernández-Montesinos, alcalde socialista, había sido fusilado días antes; y él era, además, amigo y discípulo de Fernando de los Ríos, uno de los hombres más odiados por la derecha granadina.

f) Brenan abre un camino de investigación que seguirán inmediatamente después Claude Couffon, Schonberg, Marcelle Auclair... y otros investigadores que reconocen su aportación, como Ian Gibson, Vila-SanJuan y Eduardo Castro.

g) El investigador no sólo realiza una investigación importante sobre uno de los hechos más lamentables y que más deterioraron la imagen del régimen al fusilar al poeta español más universal de su tiempo, sino que conduce una investigación que, en este caso, entendemos, se convierte en un tratado de estilo periodístico.» ${ }^{14}$

El trabajo de Brenan constituyó pues uno de los grandes hitos del periodismo de investigación en la Andalucía de la postguerra, si tenemos en cuenta las condiciones en las que se llevó a término una actividad investigadora de esta índole. En efecto, Brenan abre el camino a otros escritores, investigadores y periodistas investigadores que, más adelante, ya al final del periodo franquista y en épocas posteriores, se atrevieron a seguir con el tema, puesto que tampoco entonces, al final del franquismo, era fácil.

Entre los periodistas que desarrollaron trabajos detallados sobre la muerte de Lorca cabe destacar al granadino Eduardo Castro que indagó en el asunto con Franco todavía en el poder y, finalmente, publicó sus resultados en un libro que se editó en 1975, el mismo año de la muerte del general que detentó el poder en España durante casi cuarenta años ${ }^{15}$.

14 RAMOS ESPEJO, Antonio: El periodismo en Gerald Brenan, Tesis Doctoral inédita, Departamento de Periodismo, Universidad de Sevilla, 1998, pp. 556-557. La cursiva es del autor.

15 Véase CASTRO, Eduardo: Muerte en Granada: la tragedia de Federico García Lorca, Ed. Akal, Madrid, 1975. 
3.2.2. El «cementerio nuclear» de Hornachuelos

Un año después de la muerte de Franco salió a la calle el primer semanario andaluz de información general: Tierras del Sur, dirigido por José María Javierre, que estuvo en el mercado desde 1976 a $1979{ }^{16}$. La gran aportación de esta revista al periodismo de investigación en Andalucía fue dar a conocer la existencia de un vertedero o «cementerio atómico» ubicado en Hornachuelos, en la sierra de Córdoba, colindante con la sierra norte de Sevilla.

La repercusión que el tema tuvo y aún tiene en la actualidad constituye una prueba evidente de la importancia de una tarea periodística desarrollada por el ya fallecido escritor y periodista cordobés Sebastián Cuevas. Cuevas, una vez escuchadas sus fuentes de información, buscó por la zona el lugar exacto donde se encontraba tan singular cementerio hasta dar con él. Fue en el año 1976. En aquel momento, Cuevas era corresponsal en Córdoba de Tierras del Sur y del diario El Correo de Andalucía. En ambas publicaciones vieron la luz sus trabajos ${ }^{17}$.

3.2.3. El «Caso Almería»

Damos un pequeño salto hasta 1981. En aquel año, tres jóvenes procedentes de Santander son confundidos con etarras por la Guardia Civil cuando viajaban en un coche por tierras de Almería. En realidad, los jóvenes habían venido a Andalucía a una fiesta familiar ya que uno de ellos, emigrante andaluz en Cantabria, pretendía asistir a la comunión de su hermano pequeño en la localidad de Pechina y venía acompañado por dos amigos que nunca habían estado en Andalucía.

Poco antes de iniciar el viaje hacia Almería ETA había asesinado en Madrid al teniente general Valenzuela. Las fuerzas de seguridad del Estado fueron puestas en alerta y las circunstancias, trágicas circunstancias, hicieron que los tres jóvenes, una vez detenidos, fueran conducidos a Almería (ya habían sido interrogados en otros lugares cerca de la ciudad andaluza), donde mueren estando en poder de la Guardia Civil.

En 1982 Carlos Castillo Quero, teniente general de la Guardia Civil, fue condenado a más de veinte años de prisión, declarado culpable de la muerte de los jóvenes. El tema fue investigado por periodistas de, entre otros medios, El País, Diario 16, Diario Montañés, La Calle, Interviú... En Andalucía lo hizo Pepe Mullor para el diario Ideal, de Granada, pero, sobre todo, cabe destacar el libro

16 Sobre el tema de las revistas andaluzas de la transición consultar REIG, Ramón: «Revistas andaluzas contemporáneas (1974-1993): pequeñs historias de un oran fracaso", en Ambitos. Revista Andaluza de Contemporáneas (1974-1993). pequeñas historias de un gran fracaso», en Ambilos. Revista Andaluza de Comuvicacidad de Sevilla 1998, pp 253-275. Tambín Há en versidad de Sevilla, 1998 , pp. $253-275$. También hallará el lector abundantes datos sobre el tema en el trabajo que Manuel RUIZ ROMERO publicó en el mismo nemo des

24 de Tierras del Sur, aparecido el 25 de octubre de 1976 (el tema está en portada). En El Correo de Andalucía de ese mismo mes está presente los días 15 y 23; en ambas ocasiones se recoge en portada. 
publicado por el ya citado Antonio Ramos Espejo donde, con estilo de reportaje literario, reconstruye los hechos y aporta todos los elementos esenciales de este suceso que pasará a la historia del periodismo como «caso Almería» ${ }^{18}$.

El nombre de Ramos Espejo es representativo de una actividad investigadora muy intensa a la vez periodística y universitaria. Su dedicación y capacidad de trabajo las ha demostrado en publicaciones como Ideal, Triunfo, Diario de Granada, diario Córdoba (fue director de los dos últimos y hasta febrero del año 2000 lo ha sido de El Correo de Andalucía). Sus tareas se han centrado, como hemos podido ver, en el problema del campo andaluz y en el caso Almería, pero, además, en la guerrilla o el «maquis» en Andalucía (activistas antifranquistas que, tras la derrota de la Segunda República, se ocultaron en zonas montañosas de España desde donde siguieron combatiendo contra la Guardia Civil, encargada de neutralizarlos), o en la vida, obra y muerte de Lorca, entre otros ${ }^{19}$.

3.2.4. Investigar a los investigadores: la crítica literaria en El País

En 1984 se publica un libro que, si bien no es periodístico, sí contiene una actividad investigadora que responde a una pregunta que no pocos se hacen con frecuencia acerca de los medios de comunicación: ¿quién investiga a los investigadores? En efecto, la indagación periodística y universitaria en relación con los propios medios de comunicación no es fácil y, además, suele acarrear algunos quebraderos de cabeza a quienes osan hacerlo. No es difícil encontrar fuentes de información sino que esas fuentes quieran hablar clara y abiertamente. En ocasiones por fidelidad a la empresa pero en otras muchas por miedo a perder el puesto de trabajo.

Por tal motivo una investigación sobre los medios o sobre un determinado aspecto de los medios suele ser objeto reservado casi en exclusidad a universitarios o a otros intelectuales que se atrevan a dar el paso. Un ejemplo lo tenemos en el escritor andaluz Julio Vélez, nacido en Morón de la Frontera (Sevilla), en 1946 pero afincado en Madrid donde murió en 1992.

Velez escribió un libro en el que demostró, investigando ciertas tendencias del periodismo especializado en crítica literaria, el favoritismo que la prensa, en

18 Véase RAMOS ESPEJO, Antonio: El caso Almería, Ed. Argos Vergara, Barcelona, 1982

19 En la década de los años noventa constatamos relevantes aportaciones de Ramos Espejo. En los inicios de esa década: Ciega en Granada. Murió buscando a su hija. La hija de Brenan, Ed. Don Quijote, Granada, 1990. A mediados de la misma: El preso que huyó de Castilla, Fundación Rosario López Muñiz, Córdoba, 1996, que trata sobre la travesía que San Juan de la Cruz llevó a cabo por Andalucía, tema investigado por Gerald Brenan. Con este libro Ramos Espejo reconstruye aquel viaje. A finales de la década ha publicado Gerald Brenan. Con este libro Ramos Espejo reconstruye aquel viaje. A finales de la década ha publicado nada menos que tres libros sobre Lorca coincidiendo con el centenario del nacimiento del poeta. Entre ellos cabe destacar Garcia Lorca en los dramas del pueblo, Centro Andaluz del Libro, Sevilla, 1998, donde Ramo demuestra cómo Lorca se inspiró en noticias aparecidas en la prensa para escribir algunas de sus piezas teatrales. La característica común de estos libros es que están escritos por un reportero, por un profesional de periodismo que viaja, investiga y ofrece datos desconocidos. Simultáneamente, Ramos Espejo ha elaborad su tesina y su tesis, ambas defendidas con Sevilla, como ya se ha dicho. 
este caso el diario El País, mostraba en pro de unos poetas y no de otros, de unas editoriales concretas y de corrientes poéticas específicas. Así nació La poesía española según El País ${ }^{20}$. El libro no fue del agrado del mencionado diario y este hecho se dejó sentir en las novedades de la editorial que publicó el libro, ya desaparecida pero entonces propiedad del novelista Eugenio Suárez Galbán.

3.2.5. El sindicato clandestino de la Guardia Civil

El año 1990 es muy especial ya que los periodistas Antonio López Hidalgo y Juan Emilio Ballesteros van a publicar un magnífico libro que recogía y aumentaba los trabajos que durante un largo periodo de tiempo habían estado publicando en El Correo de Andalucía y Diario 16 Andalucía-Diario 16 edición nacional, respectivamente, sobre el sindicato clandestino que se había formado en el interior de la Guardia Civil. Las pesquisas de López Hidalgo y de Ballesteros les habían proporcionado un material que, por su abundancia y significado, era merecedor de un libro donde pudiera recopilarse con detalle ${ }^{21}$

La investigación les cuesta a sus autores no pocos quebraderos de cabeza: amenazas, atentados contra propiedades personales y un proceso judicial que llevó a la profesión periodística, fundamentalmente de Sevilla, a solidarizarse con sus compañeros $^{22}$.

20 VÉLEZ, Julio: La poesía española según El Pais (1978-1983), Ed. Orígenes, Madrid, 1984

J.E. BALLESTEROS, A. LOPEZ HIDALGO: El sindicato clandestino de la Guardia Civil, Serie Reporter, Ediciones B Grupo Z, Barcelona, 1990

22 En 1988 numerosos periodistas con ejercicio profesional en Sevilla redactaron una nota dirigida a toda 1 profesión. La reproduzco casi en su totalidad no sólo por ser ya un documento histórico sino porque no he conocido desde entonces ninguna iniciativa similar en torno a los problemas de la profesión periodística, que no son únicamente los que se desprenden del comunicado:

"Querido compañero: El próximo día 18 de Febrero van a juzgar en la Audiencia de Sevilla a dos colegas por publicar parte de un comunicado hecho público por un sindicato -clandestino en este caso-. Uno de ello ha sido condenado también días atrás por publicar una información 'con ánimo de injuriar', según la sentencia, que no entra en la veracidad de lo publicado.

Un grupo de profesionales de la información que trabajamos en Sevilla, creemos que ha llegado el momento de defender en la calle la libertad de expresión y el derecho de los ciudadanos a recibir una información libre y veraz, tal y como dice nuestra Constitución. En nuestra opinión, se trata de dos actuaciones judiciales que atentan directamente contra el artículo 20 de la Constitución Española y contra la esencia misma de nuestro trabajo en los medios de comunicación. Por eso hemos puesto en marcha lo que cariñosamente hemos denominado OPERACION 'PROTAGONISTAS POR UN DIA'.

Como dice el catedrático de Derecho Constitucional de la Universidad de Sevilla, Javier Pérez Royo, [que llevó la defensa de los dos periodistas] en el dictamen emitido sobre el escrito de acusación contra los do colegas 'cuasa indignación, por no decir vergüenza ajena tener que contestar a estas alturas de nuestra experiencia constitucional democrática, a un escrito de acusación como éste'. Según la 'regla de tres' utilizada por el titular del Juzgado número 9 de Sevilla, Joaquín Sánchez-Ugena, para procesar a los dos colegas, imagínate, por ejemplo, la que se podría armar en el País Vasco con la publicación de referencias a comunicados de ETA como también apunta el profesor Pérez Royo.

Por todo ello, hemos decidido emprender una serie de acciones reclamando libertad de expresión y derecho a una información libre. Vamos a publicar unas páginas de publicidad en solidaridad con los procesado a una ing ' '

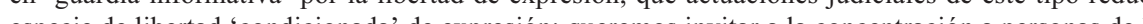


En el seno de la Guardia Civil no está permitida la formación de sindicatos al tratarse de una institución militar y no policial. Este extremo y el hecho de que su máximo líder, el cabo Rosa Recuerda, ya apartado del Cuerpo y con varios procesos a sus espaldas, se declarara abiertamente de izquierdas y mostrara públicamente aspectos de la Guardia Civil desconocidos por el público, imprimieron al asunto gran interés.

En las palabras introductorias que ambos periodistas escribieron en el libro nos dicen que todo comenzó a principios del verano de 1986 «cuando unos guardias civiles que afirmaban estar afiliados a un sindicato clandestino nos citaron en un lugar secreto para dejarse fotografiar de uniforme y encapuchados».

Más adelante añaden que el seguimiento de este caso les había costado ya, «por el momento, varios procesos judiciales y muchas horas de trabajo. A menudo, discutíamos sobre la conveniencia de eludir nombres y circunstancias que pudieran comprometer a personas que poco tenían que ver con los hechos que íbamos a narrar. No obstante, los sumarios en los que nos encontrábamos involucrados se referían a presuntos delitos de injurias y calumnias contra determinados sectores del Ejército y, por supuesto, contra el honor de la Guardia Civil. Todo ello por haber cumplido escrupulosamente con nuestro deber de informar».

Ballesteros y López Hidalgo creen que «si hubiéramos deformado la realidad, ocultando la verdad con situaciones supuestas, este informe carecería de rigor. Por ello, vaya por delante nuestro respeto a las instituciones y a las personas. Los hechos reseñados responden exclusivamente a informaciones que en su día ocuparon un lugar destacado en la prensa. En cualquier caso, hemos evitado en todo momento manifestar nuestra opinión personal o manipular situaciones comprometidas que podrían ser utilizadas con fines políticos».

las artes y el espectáculo, para que muestren su solidaridad; pretendemos juntar en Sevilla esa noche a otro trabajadores de los medios de comunicación procesados o condenados por ejercer su profesión, como Juanjo Fernández -procesado por injurias al Rey-, Xavier Vinader, Andrés Vázquez de Sola -encausado por publica unos chistes en la campaña de la OTAN- o Fernando Carrillo -procesado por algo que ni tan siquiera dijo $\mathrm{y}$, además, queremos que pongas tu imaginación en funcionamiento para sugerir otras acciones.

Naturalmente nos gustaría contar con tu apoyo. Necesitamos gente en la puerta de los juzgados para pasa la noche y dinero para traer a los colegas condenados o procesados (...). Dada la falta de un censo de periodistas de Sevilla, habrá muchos compãeros a los que no les llegue la convocatoria, por lo que te pedimos que de difundas entre muchos compañeros a los que no les llegue la convocatoria, por lo que te pedimos que la difundas entre ellos invintándolos a participar. Haz extensible la invitación tambièn a cualquier trabajador de los medios de comunicación. Además de la aportación económica y la presencia personal te pedimos también que difundas el caso entre cualquier persona, colectivo, institución o ciudadano interesado par que envíen 'postales de solidaridad' al Apartado de Correos 12.211 de Sevilla. Queremos tener una posta o telegrama de solidaridad de todos los comités de empresa posibles".

El texto lo firmaban los siguientes periodistas: Rafael Rodríguez, David Fernández Cabeza, José Aguilar, Francisco Rosell, Fernando Carrillo, Manuel Chaparro, Bonifacio R. Cañibano, Enrique Chueca, Martín Rísquez, Carmen Yanes, Santiago S. Traver, Maria José Sanchez-Apellaniz, Antonio Crespo, José A. Gavira

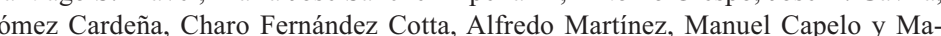
nuel Pedraz. 
Es interesante además anotar aquí otro de los detalles de las técnicas de trabajo seguidas:

«Por razones evidentes de seguridad y, por qué no, de proteccioón de los derechos fundamentales de las personas, no hemos facilitado la identidad de los guardias que dicen actuar en nombre del Sindicato Uniformado de la Guardia Civil, y tampoco la de otros ciudadanos comprometidos en esta lucha sin cuartel. Ellos mismos serían los primeros en dar la cara si no existiera la amenaza constante de una justicia militar empeñada en considerarlos reos de sedición. De todas formas, a la hora de los protagonismos, es indispensable citar a Manuel Rosa Recuerda, un funcionario de la Guardia Civil que guiado por su amor al Instituto Armado, un celo profesional recompensado con dieciocho meses de prisión, fue capaz, en solitario, de enfrentarse a las más altas jerarquías militares del Cuerpo, y poner en entredicho las palabras del ministro del Interior, José Barrionuevo, sobre su particular 'descubrimiento' de la Guardia Civil, siglo y medio después de que fuera creada por el Duque de Ahumada» ${ }^{23}$.

En lo que a Antonio López Hidalgo se refiere, nos encontramos con un caso similar al de Ramos Espejo: un periodista que investiga como tal y como profesor titular universitario, especializado en redacción periodística, materia en la que ha centrado tanto su tesina como su tesis doctoral, bajo la dirección del también periodista y profesor José Manuel Gómez y Méndez.

En una ponencia ${ }^{24}$ que en mayo de 1995 el profesor López Hidalgo expuso en la Facultad de Ciencias de la Información de Sevilla sobre su experiencia en el asunto del sindicato clandestino de la Guardia Civil, se recogía lo siguiente:

«Recuerdo aún cómo comenzó todo. El 8 de marzo de 1985, las agencias informativas difundían un despacho que aludía al comité provincial de Huelva de un sindicato clandestino de la Guardia Civil, el cual aseguraba que una cuarta parte de los guardias civiles de la 221 Comandancia del Cuerpo, con sede en esta capital, estaba asociada a esta organización ilegal. Unos meses después, un guardia vestido de paisano se personó en la redacción de El Correo de Andalucía. La telefonista le anunció la visita a Jesús González, entonces redactor de 'Sucesos' (...). Jesús me dijo que atendiera a aquel personaje porque el tema que traía entre manos rebasaba el ambito de su sección (...).

Me llamó muchos días durante muchos meses, siempre con el nombre supuesto de José Luis, desde una población que no era la suya, siempre desde una cabina telefónica. Con los meses, aprendimos a manejar algunos nombres en clave, a entendernos con medias palabras, a citarnos para recoger material informativo en el bar menos sospechoso. Pero salvo el caso de José Luis, los miembros

23 BALLESTEROS y LOPEZ HIDALGO, op. cit., pp. 7-8.

24 Dicha ponencia permanece inédita. Antonio López Hidalgo la desarrolló en el transcurso de un Seminario sobre Periodismo de Investigación al que de nuevo aludiré más adelante. 
del sindicato clandestino se identificaban con el nombre de Rigoberto I, Rigoberto II, y así sucesivamente. Algún otro apenas decía su nombre, ni falso ni verdadero, sino sólo una frase de saludo que sonaba a tarjeta de visita: 'Ya sabes quién soy'. Pensaban que cualquier teléfono podía estar intervenido; de hecho, el propio sindicato denunció algunos casos de intervenciones ilegales».

Al mismo tiempo que salía a la calle el libro escrito sobre el tema por López Hidalgo y Juan Emilio Ballesteros, ambos periodistas publicaron un texto que añadía nuevos datos acerca de los problemas internos que denunciaba el sindicato clandestino de la Guardia Civil. En la ponencia mencionada el profesor López Hidalgo, además de mostarnos algún detalle de cómo se elaboró el trabajo periodístico, resume de la siguiente manera el contenido más esencial de aquel texto:

«Escribíamos de madrugada, a partir de las doce de la noche, después de nuestra jornada laboral, hasta las cuatro o las cinco de la mañana. La primera noche comenzamos por la descripción de la casa-cuartel. Aquellos primeros folios nos llenaron de orgullo y de pesar. Al día siguiente comprobamos con estupor que el ordenador no había archivado nuestro concienzudo trabajo. Aquel capítulo de la casa-cuartel, que reconstruimos fielmente 24 horas después, lo publicó en primicia la revista Interviú la misma semana que apareció la obra en todas las librerías del país.

Por su interés, quisiera ahora recordar sólo unos párrafos, que considero elementales para entender las razones que llevaron a algunos guardias a montar un sidicato clandestino en el mismo corazón del Instituto Armado. Decían así:

'Era en la casa-cuartel donde la mujer del guardia alcanzaba el grado que tuviera su marido; donde la esposa del comandante de puesto obligaba a la mujer del número a barrer la casa del mando; donde los hijos de los guardias tenían que cortarse el pelo por indicación expresa de un superior; donde los jefes y oficiales podían llevar a cabo registros periódicos en las viviendas de los guardias; y donde sus mujeres tenían que vestir al gusto de los jefes, lo que en muchas ocasiones llevó a la prohibición explícita del uso de pantalones.

'En la casa-cuartel los mandos disponían de los guardias para realizar tareas privadas en horas de servicio; para hurtar el combustible correspondiente de los vehículos oficiales y destinarlo a consumo particular; para imponer la asistencia obligatoria a retretas, academias y otras fórmulas de apología del golpismo; para examinar a las aspirantes a esposas de guardias civiles, sometidas a interrogatorio con ánimo de salvaguardar el honor de la institución.

'Es más: en la casa-cuartel los mandos eran capaces de convertir soldados en albañiles, fontaneros, carpinteros, electricistas e incluso niñeras, bajo la amenaza del Código de Justicia Militar. Por su parte, los guardias hacían servicios de 24 horas y no contaban siquiera con las prestaciones del régimen general de la Seguridad Social.

'Lo más triste de todo esto es que ETA nos asesina como a perros y nuestros mandos militares nos pisotean, atropellan y violan nuestros derechos constitucio- 
nales'. Así sintetizaba años más tarde esta situación el secretario de Organización de un sindicato clandestino cuya existencia era impensable en esos momentos». 3.2.6. La «mafia de la construcción»

De 1991 deseamos recoger la indagación que el periodista de $A B C$, edición de Sevilla, Jesús Alvarez, comenzó a desarrollar en torno a lo que la prensa bautizó como «mafia de la construcción»: el descubrimiento de que el sindicato Comisiones Obreras presionaba a algunos empresarios para que contrataran trabajadores seleccionados por el propio sindicato y que figuraban en una lista.

Alvarez, periodista que, como buen profesional, se caracteriza por ver más allá de lo evidente y explícito, tuvo como punto de partida un simple breve que apareció tanto en su periódico como en otros: en diciembre de 1991, varios obreros de la construcción denunciaron haber sido agredidos por otros obreros que, al parecer, también eran de la construcción. Extraño. El periodista habló con la colega que había publicado la noticia en $A B C$ quien le dijo que los denunciantes habían hablado en los juzgados de Sevilla de la existencia de una lista en la que era obligatorio estar para poder trabajar en el sector y que esa lista la controlaba la rama de la Construcción del sindicato Comisiones Obreras. La compañera añadió que tanto trabajadores como contratistas tenían miedo a hablar del asunto.

El siguiente paso fue lógico: «yo le pedí a mi jefe que me liberara de cualquier otro tema durante dos días para ver si tenía suerte y podía averiguar algo» ${ }^{25}$. Al principio, Jesús Alvarez chocó contra ese miedo, contra la resistencia de las fuentes, hasta que se entrevistó con un veterano sindicalista de la Federación de la Construcción de la Unión General de Trabajadores (UGT), «quien se sinceró conmigo y me contó todo lo que estaba pasando y que era básicamente que en las obras de Sevilla, en todas las obras de Sevilla, sólo trabajaban los que estaban apuntados a una lista totalmente al margen de la ley y del INEM y que manejaban no se sabía muy bien qué dirigentes del sindicato de la construcción de CC.OO. Me habló de piquetes que agredían a los obreros que no estaban apuntados, de coches que aparecían incendiados sospechosamente y de cosas de ese tenor. No quiso que pusiera en su boca muchas de las cosas que me contó pero le arranqué la promesa de que me llamaría en cuanto se enterara de alguna nueva agresión».

El tema era tan interesante como para solicitar más tiempo: «Hablé con mi jefe y le convencí para que me concediera una moratoria para mi investigación, le pedí una semana más de dedicación exclusiva a este asunto». La moratoria fue decisiva para trabajar intensamente y clarificar los hechos. El periodista contactó con fuentes de los empresarios de la construcción que coincidieron esencialmente

25 Los entrecomillados que voy a constatar proceden de una charla que, en mayo de 1995, desarrolló el propio Jesús Alvarez en un Seminario de Periodismo de Investigación que, bajo mi coordinación, tuvo lugar en la Facultad de Ciencias de la Información de Sevilla. Dicha exposición permanece inédita. 
con la versión del sindicalista de UGT. «Hasta me dieron el teléfono al que había que llamar para apuntarse a la lista y que correspondía a uno de los que tenía CC.OO. en Sevilla». Las siguientes líneas, escritas por el propio autor del trabajo, son bien significativas:

«Para poder publicar mi reportaje tenía ya en ese momento la historia, tenía los protagonistas, tenía las víctimas, tenía los testimonios, tenía el móvil pero me faltaba el asesino, es decir, los señores que controlaban la lista y los que en definitiva decían quién podía trabajar y quién no en Sevilla.

Para poder superar ese último escollo me presenté a la mañana siguiente en la sede del sindicato de CC.OO. y haciéndome pasar por solador o por alicatador, ya no lo recuerdo exactamente, me fui a apuntar a la lista. Allí pude comprobar que efectivamente había una lista que tenía su morada en la Federación de Construcción del sindicato pero me faltaba poder demostrar que esa lista se aplicaba con métodos violentos.

Esa misma tarde me llamó el secretario de la Construcción de UGT para decirme que esa mañana un afiliado suyo había sufrido la agresión de un piquete en una obra de Sevilla por no estar en la lista. No lo pensé y nada más colgar el teléfono, llamé al número que me habían dado algunos trabajadores y contratistas y que era el que le habían dado a su vez los piquetes para que se apuntaran. Tras una espera de varios minutos pude grabar una conversación telefónica con uno de los dirigentes del sindicato de la Construcción que controlaba las listas y que fue definitiva para la publicación del reportaje. Me hice pasar por ese trabajador que había sufrido la agresión del piquete esa mañana. Tenía todos los datos, el lugar de la obra, la hora en que se produjo la agresión, la conversación mantenida con el piquete y pasé no sin algunos problemas la prueba del escepticismo inicial con que mi llamada fue recibida.

Al final, conseguí que la conversación grabada reflejara, para mi tranquilidad y para la de los abogados del periódico, todo el entramado mafioso que rodeaba el trabajo de la construcción en Sevilla, con cuotas que había que pagar para poder trabajar y en algunos casos la afiliación obligatoria al sindicato. El domingo 9 de febrero de 1992 publiqué el reportaje en el que contaba todo lo que había descubierto y al que mi director (tras cerciorarse de que podíamos afrontar una querella o cualquier iniciativa legal del entorno de CC.OO.), le dio la portada del número».

3.2.7. La guerrilla o el «maquis» en Andalucía

Ya en 1993, y para dar alguna muestra de periodismo indagador en el campo audiovisual, hemos de destacar los dos capítulos de un mismo reportaje documental que el madrileño Alfonso Arteseros, que se asentó en Sevilla cuando se dio cuenta de la «materia prima» que ofrecía Andalucía para el documental de investigación, elaboró para el programa de Canal Sur TV Ventana de la Historia. 
Los documentales se centraban en el fenómeno de la guerrilla o maquis en Andalucía, al que ya hemos aludido antes al hablar de Antonio Ramos Espejo. El mérito de Arteseros estuvo en su enorme labor de rescate documental, en la localización de protagonistas de uno y otro bando-guerrilla y Guardia Civil-, tanto en ciudades, como Granada, y en pueblos de las sierras de Málaga y Granada, y en la conexión de todo el tema con imágenes de la época, con fuentes de información independientes (como historiadores universitarios) y con fuentes de información afectadas por la tragedia de los enfrentamientos bélicos.

El documental -de 62 minutos de duración entre las dos entregas-, mereció en aquel año de 1993 el Premio Andalucía de Periodismo en su modalidad audiovisual, concedido por la Junta de Andalucía a través de la Oficina del Portavoz del Gobierno, dependiente de la Consejería de la Presidencia.

3.2.8. El crimen de Los Galindos

Francisco Gil Chaparro, periodista de El Correo de Andalucía, lleva a término en 1995 la reconstrucción de los hechos y la aportación de nuevos datos acerca del conocido como «crimen de Los Galindos», un asesinato múltiple y no resuelto que se cometió en el cortijo del mismo nombre, situado en la localidad sevillana de Paradas. El suceso inspiró a Alfonso Grosso la novela Los invitados ${ }^{26}$ que fue llevada al cine.

Los asesinatos tuvieron lugar en julio de 1975. Veinte años después, y cuando ya el delito estaba prescrito desde la óptica judicial, Gil Chaparro publicó en el citado diario un reportaje dividido en doce capítulos en los que daba a conocer algunos datos -sobre todo documentos gráficos- hasta entonces ignorados por el público.

Los reportajes fueron editados con posterioridad en un libro ${ }^{27}$ que contiene unas palabras introductorias en las que el periodista nos narra lo esencial de su método de trabajo:

«Fueron horas y horas dedicadas en exclusiva a Los Galindos, con seguidas visitas a la Hemeroteca Municipal, con continuadas entrevistas con jueces, fiscales, abogados, agentes policiales y personajes de Paradas y de su entorno, de los que en la mayoría de los casos recogí sus voces en una pequeña grabadora con la única intención de que la fidelidad y la ausencia de improvisación o la interpretación especulativa fuera la base de mi reportaje; sino más bien al contrario: la realidad de lo que cada uno de ellos me contara» ${ }^{28}$.

26 GROSSO, Alfonso: Los invitados, Ed. Planeta, Barcelona, 1978. La novela fue finalista del Premio Planeta que anualmente convoca la editorial.

27 que ant CHAPARRO, Foca la editolal. Plo Gestimonios Periodísticos, Grupo de Investigación en Estructura, Historia y Contenidos de la Comunicación,
Tán

28 GIL CHAPARRO, op. cit, p. 25. 
3.2.9. El Palmar de Troya

El fenómeno religioso que desde hace años tiene lugar en el lugar conocido por el Palmar de Troya, situado en Utrera (Sevilla) o, mejor dicho, todo lo que se esconde detrás de ese fenómeno, es un punto continuo de atracción para los periodistas investigadores. Aún no se ha llegado a ninguna conclusión solvente sobre el tema más crucial: de dónde procede el dinero que reciben estos «sacerdotes» ordenados por un «papa» fundamentalista y visionario.

No obstante, los intentos indagadores persisten. En 1996, Jorge Molina, periodista de El Correo de Andalucía, publicó una serie de extensos reportajes en los que profundizaba de manera notoria en el acontecimiento ${ }^{29}$. Las cámaras de Canal Sur TV han intentado en varias ocasiones filmar determinados «enclaves» existentes en la «basílica» que se ha construido en el lugar, así como los ritos que allí se producen. Pero lo han logrado sólo en parte puesto que las amenezas han impedido a los profesionales trabajar con detenimiento.

Un tema pues que sigue abierto a los profesionales del periodismo que trabajan en Andalucía pero que, por supuesto, trasciende bastante más allá del territorio andaluz.

3.2.10. El asunto Gil y Gil

A comienzos de 1999 Pedro de Tena publicó en el diario El Mundo ${ }^{30}$ una indagación en cuatro entregas que, aunque no prosiguió, sí mostraba las posesiones y negocios de Jesús Gil y Gil en Marbella.

Dado el significado y la proyección pública que ha alcanzado este personaje, el trabajo de Pedro de Tena adquiere a lo largo de 1999 un especial valor por cuanto en este año el empresario y alcalde de Marbella ha sido inculpado firmemente de varios delitos y relacionado con la mafia, al tiempo que, sin embargo, la implantación del Grupo Independiente Liberal (GIL), su partido, gana influencia social y política, por ahora en Andalucía (provincias de Málaga y Cádiz) y en las plazas españolas de Ceuta y Melilla.

Cuando concluimos este trabajo, en noviembre de 1999, Gil había anunciado su «desembarco» en Madrid y su deseo de aspirar a la presidencia de la nación, objetivos que el propio diario El Mundo, por medio de diversos reportajes muy bien documentados, se ha encargado de frustrar desde su redacción central en Madrid en una dinámica más política que periodística, como ya se ha indicado.

De todas formas, Pedro de Tena ya había destacado en el citado diario, en su etapa como delegado en Andalucía del rotativo, como activo periodista indagador durante casi toda la década de los noventa puesto que, desde que a finales de

29 Véanse los reportajes de Jorge MOLINA que aparecieron en El Correo de Andalucía los días 9, 10, 11, 12 , 13 y 14 de abril de 1996

30 Véase El Mundo entre los días 20 a 25 de enero de 1999. 
los ochenta estallara el «caso Guerra», de Tena desarrolló una muy intensa actividad aportando nuevos datos y soportando también serias presiones ${ }^{31}$.

\section{Conclusión}

Andalucía ha sido escenario de una abundante actividad investigadora desde la óptica periodística. Los orígenes próximos de esta actividad, salvando las distancias en lo que se refiere a métodos de trabajo con la actualidad, pueden situarse a finales del siglo XIX, época en la que el problema de la tierra atrae a escritores como Azorín y Clarín, que llegan en calidad de «enviados especiales», como se diría ahora, de periódicos que se editaban en Madrid.

El paso del tiempo nos ha proporcionado más datos: el hispanista Gerald Brenan se convierte en los años cuarenta en el primer investigador de la muerte de Lorca. Ya en nuestros días, destaca en los años ochenta la reconstrucción de los hechos del «caso Almería» por parte de Antonio Ramos Espejo; a comienzos de la década de los años noventa, sobresale la investigación que Juan Emilio Ballesteros y Antonio López Hidalgo desarrollan en torno al sindicato clandestino que se había formado en el seno de la Guardia Civil.

Hay una característica en la mayoría de los casos constatados: el hecho de que trascienden las fronteras de Andalucía para tomar relevancia nacional e incluso, a veces, internacional.

31 Sobre este tema he de apuntar dos cuestiones: primera, que sé de esas presiones por el propio Pedro de Tena: segunda, que nunca he considerado el «caso Guerra» periodismo de investigación sino el resultado de luchas segunda, que nunca he considerado el «caso Guerra» periodismo de investigación sino el resultado de luchas
internas entre segmentos de poder enfrentados y en una dinámica de venganzas. Lo que sucede es que, una internas entre segmentos de poder enfrentados y en una dinamica de venganzas. Lo que sucede es que, una
vez que el asunto llega a la prensa, no pocos periodistas, entre ellos Pedro de Tena, se vieron obligados a seguir «tirando de los hilos» y ahí sí existió una actividad indagadora relevante. 